\title{
Influence of Clearance Flow on Dynamic Hydraulic Forces of Pump-Turbine during Runaway Transient Process
}

\author{
Xiaoxia Hou ${ }^{1}$, Yongguang Cheng ${ }^{1, *(\mathbb{C}, \text { Zhiyan Yang }}{ }^{1}$, Ke Liu $^{1}$, Xiaoxi Zhang ${ }^{2}$ and Demin Liu ${ }^{3,4}$ \\ 1 State Key Laboratory of Water Resources and Hydropower Engineering Science, Wuhan University, \\ Wuhan 430072, China; xxhouwh@whu.edu.cn (X.H.); mry@whu.edu.cn (Z.Y.); liukeyf@whu.edu.cn (K.L.) \\ 2 School of Environmental Science and Engineering, Xiamen University of Technology, Xiamen 361024, China; \\ zhangxiaoxi@xmut.edu.cn \\ 3 Dongfang Electric Machinery Co., Ltd., Deyang 618000, China; liudemin@dongfang.com \\ 4 College of Water Resource \& Hydropower, Sichuan University, Chengdu 610065, China \\ * Correspondence: ygcheng@whu.edu.cn
}

Citation: Hou, X.; Cheng, Y.; Yang,

Z.; Liu, K.; Zhang, X.; Liu, D.

Influence of Clearance Flow on

Dynamic Hydraulic Forces of

Pump-Turbine during Runaway

Transient Process. Energies 2021, 14 ,

2830. https://doi.org/10.3390/

en14102830

Academic Editor: Phillip Ligrani

Received: 12 April 2021

Accepted: 12 May 2021

Published: 14 May 2021

Publisher's Note: MDPI stays neutral with regard to jurisdictional claims in published maps and institutional affiliations.

Copyright: $\odot 2021$ by the authors. Licensee MDPI, Basel, Switzerland. This article is an open access article distributed under the terms and conditions of the Creative Commons Attribution (CC BY) license (https:// creativecommons.org/licenses/by/ $4.0 /)$.

\begin{abstract}
The clearance flow around the pump-turbine runner has significant influences on unit vibrations, which may cause accidents in transient processes. The dynamic hydraulic forces and flow patterns in the clearance flow channel (CFC) of a low specific-speed pump-turbine were analyzed based on 3D CFD simulations during the runaway oscillating process. It is shown that the axial force of the runner periodically fluctuates with large amplitudes, and its components in CFC and the main flow channel (MFC) demonstrate a similar significance level. The CFC component was formulated as a function of the clearance inlet pressure and rotational speed, while the MFC component as a function of the momentum changing rate and the runner outlet pressure force. The fluctuation of runner radial force is mainly caused by the flow evolution in MFC, however, the flow in CFC aggravates it. The pressure in $\mathrm{CFC}$ shows a few pulsating signals from MFC, and the radial pressure drop in CFC is proportional to the square of both radius and rotational speed. In CFC, strong rotating shear flow containing a velocity core region in the circumferential direction is formed, and rotational speed is the dominant factor.
\end{abstract}

Keywords: pump-turbine; runaway transient process; runner forces; clearance leakage; clearance flow patterns

\section{Introduction}

As the main way to store energy on large scale, the pumped-storage power generally undertakes functions such as peak load regulation, valley load regulation, frequency modulation, phase modulation and spinning reserve in the power grid, to match with thermal, nuclear, wind and solar powers. Fast and frequent transitions of operating modes, along with various off-design operations are needed for pump-turbines [1,2]. During violent transient processes, many dynamic instability problems, such as unit vibration, powerhouse noise and excessive water hammer were reported frequently [3-5], even if the extreme accidents of rotor lifting and rotor-stator crashing happened occasionally [6,7]. These accidents were actually caused by the fluctuations of runner forces during transients. The runner forces can be classified into two parts: the force in the main flow channel (MFC) and the force in the clearance flow channel (CFC), which is the small gaps between the rotating and stationary parts of the pump-turbine. It was recognized that the pressure, distribution and evolution in CFC have significant influences on the total runner forces. However, most of the existing research on runner forces only focused on the flow in MFC, because of the difficulties in measuring and simulating the flow in CFC.

Regarding the force in MFC, Dai et al. [8] investigated the axial forces of the pumpturbine in Tianhuangping hydropower station and found that the axial force measured by the model test was greatly different from the prototype unit, due to the difficulty in 
ensuring similarity. Therefore, numerical simulation is the main means to study runner forces. Xia et al. $[9,10]$ numerically studied pressure pulsations and runner forces of a model pump-turbine during the runaway transient process and found that the reverse flow around the runner inlet could cause high-frequency axial force fluctuations. Yang et al. [11] pointed out that the unstable vortex structure in MFC of the pump-turbine is another reason for the force fluctuations during the runaway transient process after pump-trip. Widmer et al. [12] found that the rotating stall in the flow channel of the pump-turbine was the main reason resulting in the instability of the runner during the turbine braking process. Furthermore, during the load rejection transient process, Fu et al. [13] concluded that the fluctuation frequency of axial force was caused by the reverse flow and helical vortex flow in the draft tube. All above studies on force fluctuations neglected the hydraulic force in CFC, which should be considered in analyzing the possibilities of rotor lifting and rotor-stator crashing.

Up to now, the force in CFC was rarely studied. Most studies on CFC mainly paid attention to the sealing ring, which is the most important component of CFC. The sealing ring was made into various zigzag shapes to increase the local kinetic energy loss, so as to reduce the fluid leakage [14]. One of the most common research directions was to compare the sealing effect of different sealing types, such as straight-through, stepped and labyrinth type [15-17]. Another was to explore the influence of sealing size on the clearance leakage and unit efficiency $[18,19]$. Koirala et al. [20] found that the leakage increased with the increase of sealing size, but the energy conversion efficiency of the turbine decreased. Dong et al. [21] simulated the clearance flow of the pump-turbine and found that the leakage flow rate could not only cause volume loss, but also change the mainstream flow patterns. Moreover, Jürgen et al. [22] and Čelič et al. [23] found that the unit efficiency agreed with the reality better when CFC was considered. In recent years, some researchers began to study the force in CFC. Wu et al. [24,25] studied the axial hydraulic force of pump-turbine with high head and found that the clearance leakage had a sensitive influence on the axial hydraulic force, which was the main hydraulic factor leading to rotor lifting. Fu et al. [26] and Zhang et al. [27] compared the axial force with and without the clearance flow during the load rejection process and confirmed that there was a huge difference in value and direction. However, the correlated mechanism was not analyzed thoroughly. In summary, the research on the clearance flow patterns and clearance hydraulic force of pump-turbine are still very scarce, and the influence mechanism of clearance flow is not clear. How clearance flow and forces change during the transient process, and how they affect the total runner force, are needed to be clarified.

Due to the small size and complex shape of CFC, model tests and prototype observations are largely limited, and computational fluid dynamics (CFD) has become an important method to study the clearance flow. In this paper, the dynamic hydraulic forces and flow patterns in CFC of a low specific-speed pump-turbine were analyzed based on three-dimensional (3D) CFD simulations of the runaway oscillating process. The analysis focused on the influence degree of clearance hydraulic force on the runner forces, the influence factors and change mechanism of hydraulic forces, the change laws of clearance flow patterns and pressure distribution in CFC.

\section{CFD Simulation Methods for the Pump-Turbine}

\subsection{Pump-Turbine Model}

In this study, a prototype pump-turbine with specific-speed $n_{\mathrm{q}}=30.5$ (calculated by Equation (1)) was selected. The computational domain contains MFC and CFC. As shown in Figure 1, the MFC is composed of spiral-casing, stay and guide vanes, runner and draft tube; the CFC contains the clearance region between the hub upper surface (rotating surface) and the cover lower surface (stationary surface), denoted as CHC, and the clearance region between the shroud lower surface (rotating surface) and the bottom ring upper surface (stationary surface), denoted as CSB; the CHC domain contains clearance inlet, pressure external cavity, sealing ring, pressure internal cavity, clearance outlet and 
pressure equalizing pipes (PEP). The sealing sizes of CHC and CSB are $1.4 \mathrm{~mm}$ and $1.6 \mathrm{~mm}$, respectively. The relevant parameters of the runner are shown in Table 1.

$$
n_{\mathrm{q}}=\frac{n_{\mathrm{r}} \sqrt{Q_{\mathrm{r}}}}{H_{\mathrm{r}}^{3 / 4}}
$$

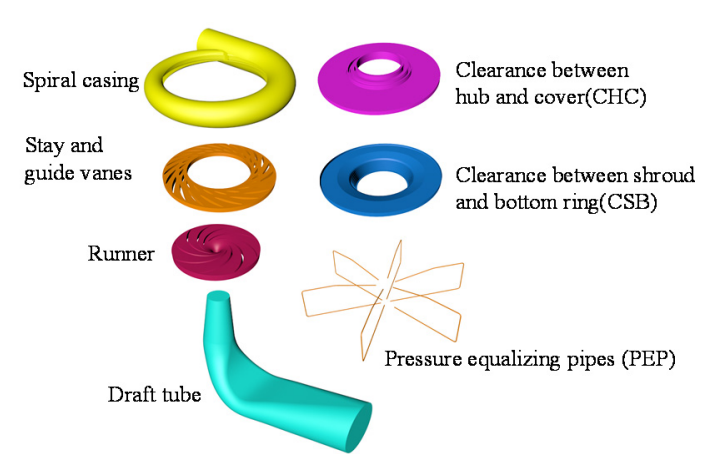

(a)

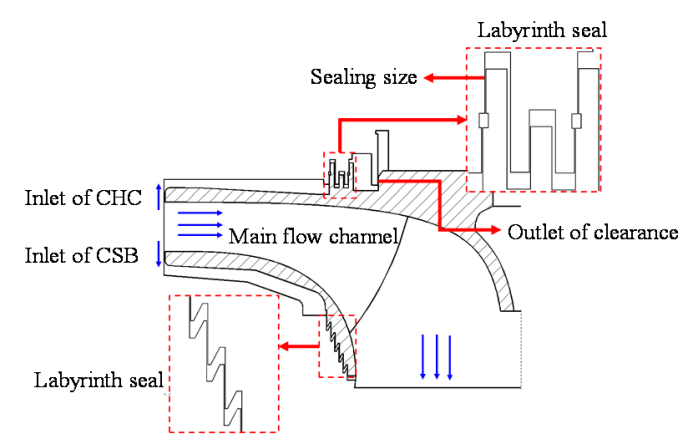

(b)

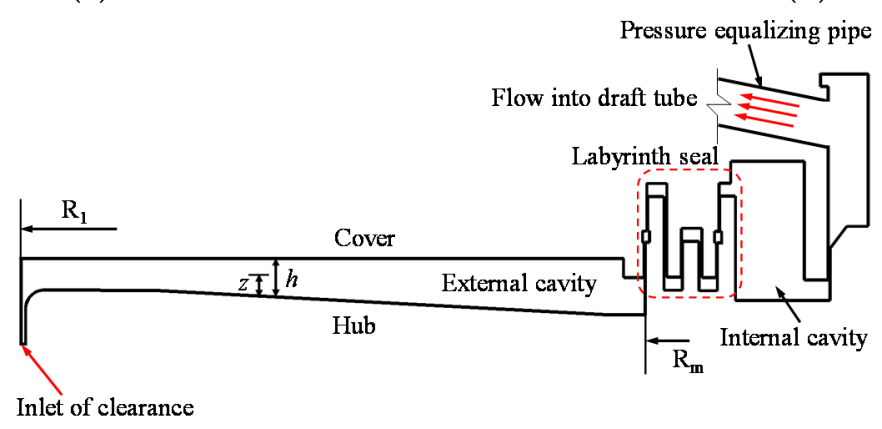

(c)

Figure 1. 3D model of the pump-turbine. (a) Computational domains. (b) Flow channels. (c) Detail drawing of CHC.

Table 1. Basic parameters of the runner.

\begin{tabular}{cccc}
\hline Parameter & Value & Parameter & Value \\
\hline Specific speed $n_{\mathrm{q}}\left(\mathrm{m}, \mathrm{m}^{3} / \mathrm{s}\right)$ & 30.5 & Guide vane height $b_{0}(\mathrm{~m})$ & 0.3 \\
Rotational speed $n_{\mathrm{r}}(\mathrm{rpm})$ & 500 & Blade number $z_{\mathrm{b}}$ & 9 \\
Rated discharge $Q_{\mathrm{r}}\left(\mathrm{m}^{3} / \mathrm{s}\right)$ & 62.43 & Guide vane number $n_{\mathrm{gv}}$ & 22 \\
Rated output $P_{\mathrm{r}}(\mathrm{MW})$ & 357 & Stay vane number $n_{\mathrm{sv}}$ & 22 \\
Rated head $H_{\mathrm{r}}(\mathrm{m})$ & 655 & Sealing size of CHC $(\mathrm{mm})$ & 1.4 \\
Runner inlet diameter $D_{1}(\mathrm{~m})$ & 4.260 & Sealing size of CSB $(\mathrm{mm})$ & 1.6 \\
Runner outlet diameter $D_{2}(\mathrm{~m})$ & 1.955 & Level of the sealing ring & 7 \\
\hline
\end{tabular}

\subsection{Multi-Scale Grid Coupling}

Compared with MFC, CFC is very thin and needs to be discretized with extremely small grids. Therefore, appropriately connecting the macro-scale grids in MFC with the micro-scale grids in CFC is the key to effectively transfer the numerical values. The multi-scale grid coupling method was used (Figure 2a), and a transient region was set between the guide vanes and the runner. The macro-scale grids were used in the main flow direction, while the micro-scale grids were used in the clearance channel direction, which were suitable for the micro-scale grids in the clearance channel. The grids of the hub upper surface (rotating surface) are shown in Figure 2b. 


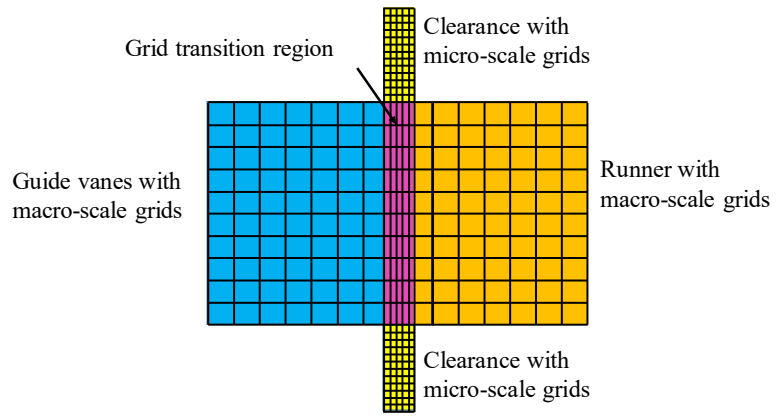

(a)

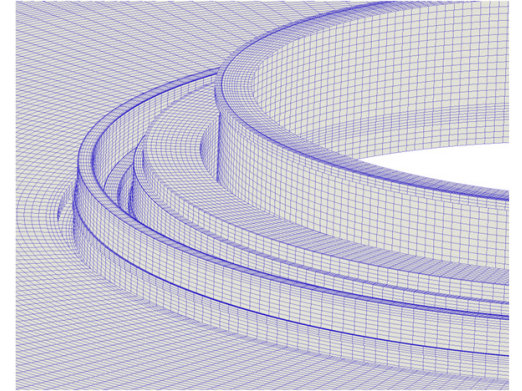

(b)

Figure 2. Simulation grid discretization. (a) Grid coupling of different scales. (b) Grids on the hub upper surface.

\subsection{Grid Independence Verification}

Hybrid grids were generated by commercial software ANSYS ICEM. Structural hexahedral grids were used in all domains except for the guide vane domain, in which unstructured wedge-shaped grids were used. Since the unstructured grid in guide vane domain is better to adapt to the dynamic grid, which will be applied in the load rejection transition process in the future. Grid independence verification adopted five stepwise levels, from 3.73 to $4.10,4.61,5.17,5.55$ and 6.00 million, respectively. In the rated operating condition, when the number of cells was more than 4.61 million, the variation ranges of torque and discharge were $0.7 \%$ and $0.2 \%$, respectively. At the off-design operating condition (the discharge was half of the rated discharge), the moment variation range was small enough to $1.3 \%$. Therefore, the 5.17 million grid level was used, and the grid allocation in each computational domain was shown in Table 2 . In order to verify the grid sensitivity of the clearance regions, the influence of the $\mathrm{CHC}$ grid number on the leakage was further analyzed. The leakage remained relatively constant (within $0.32 \%$ ) when the cell number of $\mathrm{CHC}$ is more than 0.51 million, therefore, the grids of 0.74 million and 0.6 million were used in CHC and CSB, respectively.

Table 2. Number of cells (million).

\begin{tabular}{ccccc}
\hline Domains & Spiral-Casing & Vanes & Transition Region & Runner \\
\hline number & 0.71 & 1.06 & 0.16 & 0.75 \\
Domains & Draft-Tube & CHC & CSB & PEP \\
number & 0.81 & 0.74 & 0.60 & 0.34 \\
\hline
\end{tabular}

\subsection{Numerical Methods}

The finite volume method of commercial software Fluent was used for the simulation. Combining the advantage of RANS and LES model, the SAS turbulence model was generally applied to the transient processes of the turbine, and good results were obtained $[9,10,28]$. Therefore, the SAS-SST turbulence model and the SIMPLEC pressure velocity coupling algorithm were selected. For the prototype pump-turbine with a large size, it is almost impossible to meet $y+=1$ because of the high Reynolds number; to ensure the accuracy of the turbulence model of SAS, the y+ value was more than 30 in the whole domain, so that the wall function approach can be used in the simulation. The second order scheme was used in space and time discretization. The time step size was set as $0.001 \mathrm{~s}$.

(1) Boundary conditions

The total pressure of 7,393,218.21 Pa was set at the inlet of the spiral casing, and the static pressure of $979,234.2 \mathrm{~Pa}$ was set at the outlet of the draft tube. All the walls were set as the non-slip wall. 


\section{(2) Rotational speed}

During the runaway transient process, the rotational speed of each time step is determined by the water torque, which can be calculated as follows:

$$
\omega_{\mathrm{t}}=\frac{T}{J} \Delta t+\omega_{\mathrm{t}-\Delta \mathrm{t}}
$$

where $\omega_{\mathrm{t}-\Delta \mathrm{t}}$ and $\omega_{\mathrm{t}}$ are the rotational speed at previous and current timesteps; $\Delta t$ is the timestep size; $T$ is the hydraulic torque acting on the runner, which contains the torque of MFC and CFC; $J$ is the rotational inertia of the rotating part, $1.125 \times 10^{6} \mathrm{~kg} \cdot \mathrm{m}^{2}$.

In addition, the hub upper surface and the shroud lower surface were set as rotational walls, rotating with the same speed as the runner.

(3) Definition of dimensionless parameters

In order to generally describe the characteristics of the pump-turbine, the pressure coefficient $\phi$ and velocity coefficient $\varphi$ were defined by Equations (3) and (4), respectively. The radial radius coefficient of the external cavity in $\mathrm{CHC} r^{\prime}$ was defined by Equation (5). The larger the $r^{\prime}$, the closer to the outer edge of CHC.

$$
\begin{gathered}
\phi=\frac{p}{\rho u_{1}^{2} / 2}=\frac{p}{\rho \omega_{0}^{2} R_{1}^{2} / 2} \\
\varphi=\frac{v}{u_{1}}=\frac{v}{\omega_{0} R_{1}} \\
r^{\prime}=\frac{r-R_{\mathrm{m}}}{R_{1}-R_{\mathrm{m}}}
\end{gathered}
$$

where $p$ is the pressure; $\rho$ is the density of water; $\omega_{0}$ is the rated rotational speed; $u_{1}$ is the circumferential velocity at $R_{1}$ in the rated operating condition; $v$ is the flow velocity; $R_{1}$ is the radius of the runner inlet, equivalent to the maximum radius of CFC; $r$ is the radius in the clearance area; $R_{\mathrm{m}}$ is the radius at the inlet of the sealing ring of $\mathrm{CHC}$ (Figure 1c).

Due to the great differences of force values in different operating conditions, in order to intuitively and concisely describe forces, the axial forces and radial forces were dimensionless processed as follows:

$$
\begin{gathered}
F_{\mathrm{z}}=\frac{N_{\mathrm{z}}}{A_{\mathrm{z}}}=\frac{4 N_{\mathrm{z}}}{\rho \mathrm{g} H \pi \mathrm{R}_{2}^{2}} \\
F_{\mathrm{r}}=\frac{N_{\mathrm{r}}}{A_{\mathrm{r}}}=\frac{N_{\mathrm{r}}}{\rho \mathrm{gHb} b_{0}}
\end{gathered}
$$

where $F_{\mathrm{z}}$ and $F_{\mathrm{r}}$ are the dimensionless axial force and radial force, respectively; $N_{\mathrm{z}}$ and $N_{\mathrm{r}}$ are the original axial force and radial force, respectively; $b_{0}$ is the guide vane height; $R_{2}$ is the radius of runner outlet (in turbine mode); the axial reference force $A_{\mathrm{z}}$ and the radial reference force $A_{\mathrm{r}}$ are defined by multiplying rated head $H_{\mathrm{r}}$ with the runner outlet and inlet areas at the rated working point, respectively, with $A_{\mathrm{z}}=19,244 \mathrm{kN}$ and $A_{\mathrm{r}}=1924 \mathrm{kN}$.

\section{Clearance Force and Flow Results}

\subsection{Macro Parameters during the Runaway Transient Process}

The initial point of the runaway transient process is the rated operating condition. In the case of load rejection transients of pump-turbines, if the guide vanes fail to close, the runner rotational speed, discharge and torque will begin to oscillate periodically with constant and unattenuated amplitudes (Figure 3a). The process starts from the turbine mode ( $t=0 \mathrm{~s}$ to $3.03 \mathrm{~s})$ to the turbine braking mode $(t=3.03 \mathrm{~s}$ to $3.41 \mathrm{~s})$ and the reverse pump mode ( $t=3.41 \mathrm{~s}$ to $5.15 \mathrm{~s}$ ); then returns from the reverse pump mode to the turbine braking mode ( $t=5.15 \mathrm{~s}$ to $5.77 \mathrm{~s}$ ) and the turbine mode ( $t=5.77 \mathrm{~s}$ to $8.14 \mathrm{~s})$. Once the load is rejected at $t=0 \mathrm{~s}$, the generator resistance torque sharply drops to zero, and the 
runner rotational speed increases gradually due to the imbalance of unit torque. With the increase of rotational speed, the discharge gradually decreases due to the influence of runner centrifugal force. After reaching the maximum runaway speed $(t=3.03 \mathrm{~s})$, the unit enters the turbine braking mode, in which the hydraulic torque becomes negative, and the discharge rapidly decreases to zero $(t=3.41 \mathrm{~s})$. Subsequently, the flow reverses and gets into the reverse pump mode, in which the reverse discharge sharply increases to its maximum. Since the rotational speed continues to decrease, the effect of reverse hydraulic torque gradually weakens, the flow returns to the turbine direction and the unit goes back to the turbine braking mode. In the turbine braking mode, the reverse hydraulic torque decreases rapidly because of the increased positive discharge, then the unit returns to the turbine mode and the hydraulic torque changes to the positive direction. The above description is for the first cycle, and the following process includes many similar oscillating cycles. As shown in Figure 3b, the operating trajectory shows periodic annular trajectory in the S-shaped region, and the oscillation amplitude cannot be attenuated. The runaway oscillation phenomenon is a typical feature of low specific-speed pump-turbines [29], in which the operating trajectory enters the reverse pump mode deeply, and is easier to produce runaway oscillations, the mechanism of the S-shaped characteristics and the runaway instability could be found in reference [9].

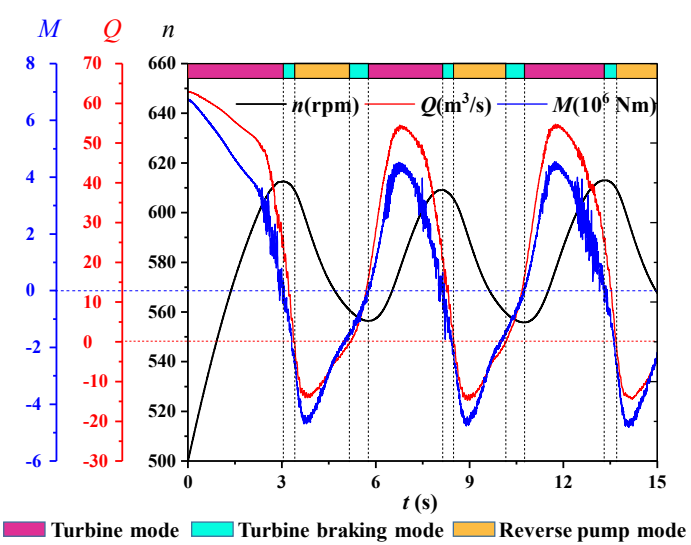

(a)

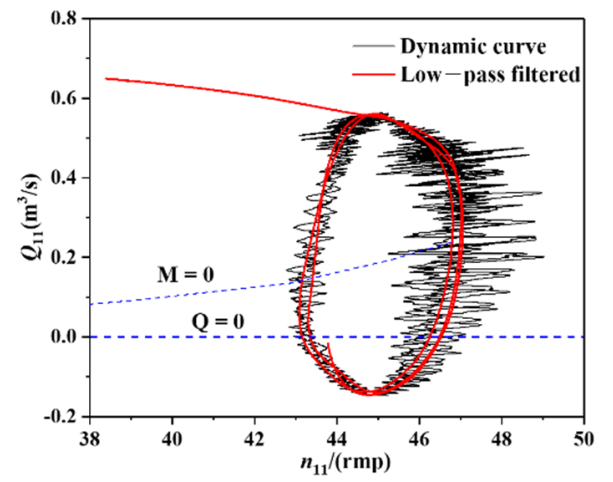

(b)

Figure 3. Oscillating characteristics during the runaway transient process. (a) Macro parameters. Q: Discharge; n: Rational speed; M: Moment of the runner. (b) Operating trajectory in the $n_{11}-Q_{11}$ plane.

\subsection{Runner Force Oscillating Characteristics}

\subsubsection{Axial Forces}

Assuming the shaft of the pump-turbine is vertical, the schematic of the runner axial forces can be described with Figure 4 , where $F_{1}$ is the axial hydraulic force in MFC, in the upward or downward direction; $F_{2}$ is that in $\mathrm{CHC}$, in the downward direction; $F_{3}$ is that in CSB, in the upward direction; $F_{4}$ is the self-weight of the runner, in the downward direction; $F_{5}$ is the buoyancy force, in the upward direction; $F_{6}$ is the axial force acting on the shaft end, in the downward direction. The total axial force on the runner is the summation of these six forces. Compared with other axial forces, the summation of $F_{4}$ and $F_{5}$ is smaller enough to be neglected. Since the value of $F_{6}$ is fixed, it will not be discussed in this paper. Only the axial hydraulic force $F_{1}$ in MFC and that $F_{\mathrm{C}}$ in CFC are analyzed because they are the main components of the total axial hydraulic force. To make clear discussions, MFC axial force $F_{1}$ can be divided into the axial force $F_{\mathrm{b}}$ acting on the blades, $F_{\mathrm{u}}$ acting on the hub lower surface and $F_{\mathrm{d}}$ acting on the shroud upper surface, namely, $F_{1}=F_{\mathrm{b}}+F_{\mathrm{u}}+F_{\mathrm{d}}$; CFC axial force $F_{\mathrm{c}}$ can be divided as the clearance force $F_{2}$ in CHC and the clearance force $F_{3}$ in CSB, namely, $F_{\mathrm{C}}=F_{2}+F_{3}$. The variation law of total axial hydraulic force $F_{\mathrm{W}}\left(F_{\mathrm{w}}=F_{1}+F_{2}+F_{3}\right)$ will represent the change of the total runner force. The forces were directly monitored in the software. 


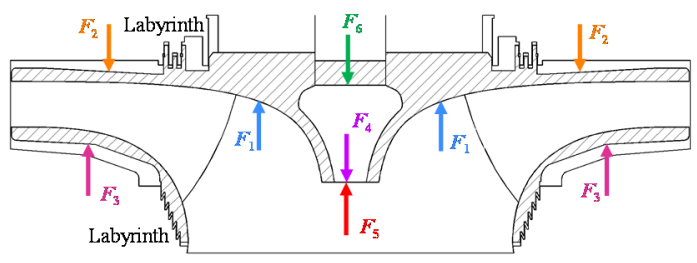

Figure 4. Schematic of axial forces.

In the rated operating condition, the values of the axial force components are shown in Figure 5. In MFC, $F_{\mathrm{b}}=-0.19$ is the smallest; $F_{\mathrm{u}}=2.4$ and $F_{\mathrm{d}}=-2.01$ are larger in values but opposite in directions. These result in a small upward $F_{1}=0.20$, which is only $10 \%$ of $F_{\mathrm{u}}$. In CFC, $F_{2}=-2.92$ in $\mathrm{CHC}$ and $F_{3}=2.84$ in CSB possess larger values than those in MFC. Similarly, the two larger clearance forces counteract due to their opposite directions, resulting in a small downward $F_{\mathrm{c}}=-0.13$, which is only $4.4 \%$ of $F_{2}$. Since the CFC axial force $F_{\mathrm{c}}$ and the MFC axial force $F_{1}$ have similar value levels but opposite directions, their counteract result is very small, namely the total axial hydraulic force $F_{\mathrm{w}}=0.07$, which contributes to a professional runner design. The above analysis proves that the force in CFC is extremely important to the total runner force, which should not be ignored.

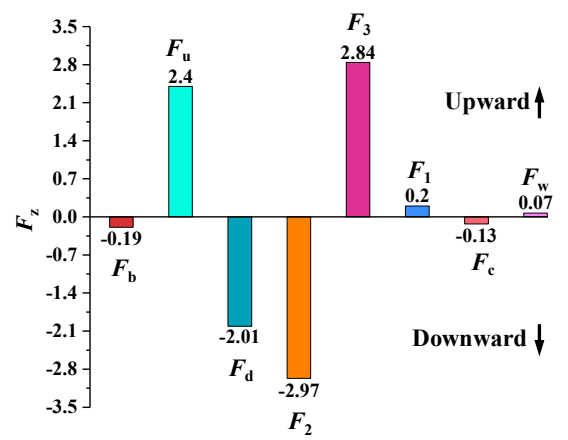

Figure 5. Dimensionless axial forces in the rated operating condition.

During the runaway oscillating process, $F_{\mathrm{w}}$ periodically fluctuates with large amplitudes, getting the upward maximum before approaching the runaway point and the downward maximum around turbine braking mode (Figure 6a). The severe fluctuation is corresponding to the S-shaped region in the characteristic plane (Figure $3 \mathrm{~b}$ ). The histories of $F_{1}$ in MFC and $F_{\mathrm{c}}$ in CFC are different, with $F_{1}$ always upward and $F_{\mathrm{c}}$ most of the time downward. The value of $F_{\mathrm{c}}$ decreases rapidly when the working point transits from turbine mode to turbine braking mode, and changes to upward when approaching the runaway point. In this $F_{\mathrm{c}}$ upward period, $F_{\mathrm{W}}$ reaches at its maximum with a value about 0.2 to 0.3 , which may induce rotor lifting. The upward $F_{1}$ gradually decreases in turbine braking mode and near the same time $F_{\mathrm{c}}$ reaches its downward maximum. The superposition of these two leads to the largest downward $F_{\mathrm{w}}$ around the turbine braking mode, which is easy to cause bearing damage. $F_{\mathrm{C}}$ and $F_{1}$ demonstrate a similar significance level, and the maximum value of $F_{\mathrm{c}}$ is 1.3 times of $F_{1}$. This means again that the forces in CFC must be considered in transient analysis. The following will further explain why the total axial force has a large difference between considering and without considering clearance hydraulic force, and how can the axial forces in both MFC and CFC be evaluated. 


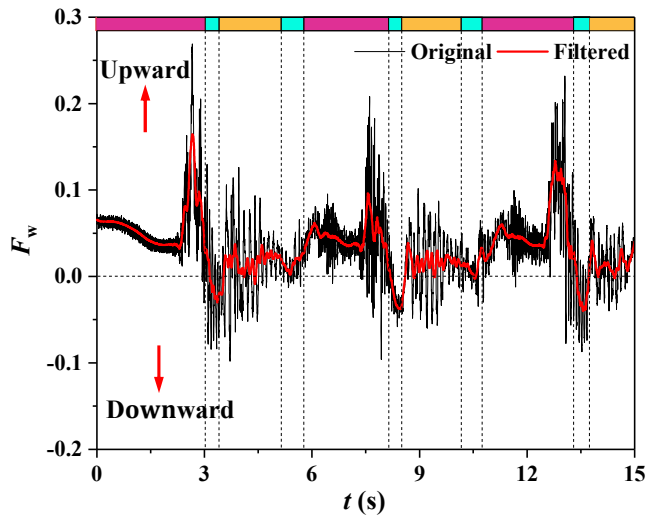

(a)

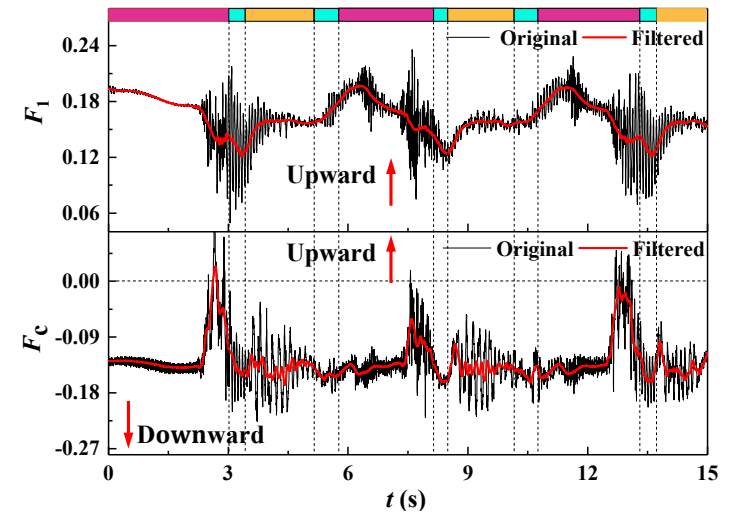

(b)

Figure 6. Histories of axial forces during runaway oscillating process. (a) Histories of $F_{\mathrm{w}}$. (b) Histories of $F_{1}$ and $F_{\mathrm{c}}$.

(1) Axial hydraulic force in MFC $-F_{1}$

For Francis pump-turbines, assuming the water flows in or out of the runner inlet (in turbine mode) in the radial direction, while flows out or in the runner outlet (in turbine mode) in the axial direction. Taking the water inside the runner as the control body, the resultant force $\sum F$ acting on the control body is equal to the momentum change of the system according to the momentum theorem, as follows:

$$
\sum F=\frac{\partial}{\partial \mathrm{t}} \iiint_{V} \rho v \mathrm{~d} V+\iint_{S} \rho v^{2} d s
$$

where $v$ is water flow velocity, $V$ is the volume of the control body, $s$ is the closed surface of the control body. The first term on the right-hand of Equation (8) is the momentum change with time of control body, and is mainly internal consumption in the control body, which is volume force essentially. However, the surface force plays a predominant factor for pump-turbines. Therefore, the value of the first term is very small, which will be validated by following simulation. The second term is the momentum changing rate of water flowing out the control body. With the special shape of the control body considered, the resultant force $\sum F$ can also be expressed as the vector sum of the axial force $F_{\mathrm{s}}$ acting on the water body and the axial pressure force $F_{\mathrm{p}}$ at the runner outlet, as follows:

$$
\sum F=F_{\mathrm{s}}-F_{\mathrm{p}}
$$

Since $F_{1}$ is the reaction force of $F_{\mathrm{s}}, F_{1}=-F_{\mathrm{S}}$ can be submitted to Equation (9):

$$
F_{1}=-F_{\mathrm{s}}=-\left(F_{\mathrm{p}} \pm \rho \frac{Q^{2}}{A_{2}}\right)
$$

where $Q$ is the discharge, and $A_{2}$ is the cross-sectional area of the runner outlet. The positive sign of the second term in Equation (10) means that the water flows out the runner outlet, while the negative sign means that the water flows into the runner outlet.

According to Equation (10), the axial force in MFC $F_{1}$ is determined by two terms, the axial pressure force of the runner outlet $F_{\mathrm{p}}$ and the momentum changing rate $\rho Q^{2} / A_{2}$. During the runaway transient process, the variation law of $F_{\mathrm{p}}, \rho Q^{2} / A_{2}$, and $F_{1}$ are shown in Figure 7a. The value of $\rho Q^{2} / A_{2}$ is related to the discharge, while $F_{\mathrm{p}}$ is determined by the pressure of the runner outlet. In order to verify the correctness of Equation (10), the simulated $F_{1}$ is compared with the calculated one by Equation (10) (Figure $7 \mathrm{~b}$ ), and the two are in good agreement. $\rho Q^{2} / A_{2}$ reaches the largest after re-entering the turbine mode, which results in the maximum of $F_{1}$. After entering the turbine braking mode, $F_{1}$ decreases to the minimum because of the smaller $F_{\mathrm{p}}$ and $\rho Q^{2} / A_{2}$. 


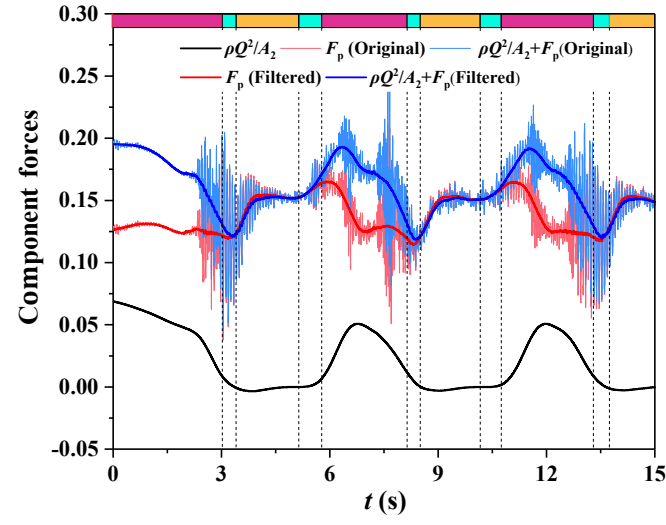

(a)

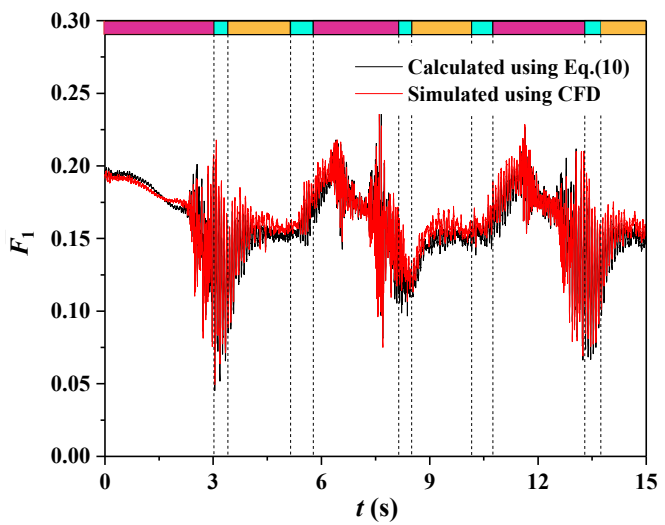

(b)

Figure 7. Histories of axial forces in MFC during the runaway transient process. (a) Axial force components. (b) Comparison of $F_{1}$ between values by simulation and by Equation (9).

Equation (10) is valuable, because we can use it to estimate the MFC axial force history if borrowing the basic results of $1 \mathrm{D}$ transient simulation.

(2) Axial hydraulic forces in $\mathrm{CFC}-F_{2}$ and $F_{3}$

The change laws of $F_{2}$ and $F_{3}$ are different from $F_{1}$ (Figure 8a). However, $F_{2}$ and $F_{3}$ possess the same changing trend of magnitude, but in opposite direction. The pressure in the clearance cavity, transmitted from the main flow channel (Section 3.3.1), is the source of the axial forces in CFC. The variation law of $\left|F_{2}\right|$ matches well with that of $\mathrm{CHC}$ clearance inlet pressure $P_{\text {in }}$ (dimensionless pressure), indicating that the dominant factor of the clearance axial force is the clearance inlet pressure (Figure $8 \mathrm{~b}$ ). However, the pressure in the clearance region is also influenced by the runner rotational speed. Therefore, the clearance axial force can be represented as a function of the clearance inlet pressure and rotational speed. (Section 3.3.3).

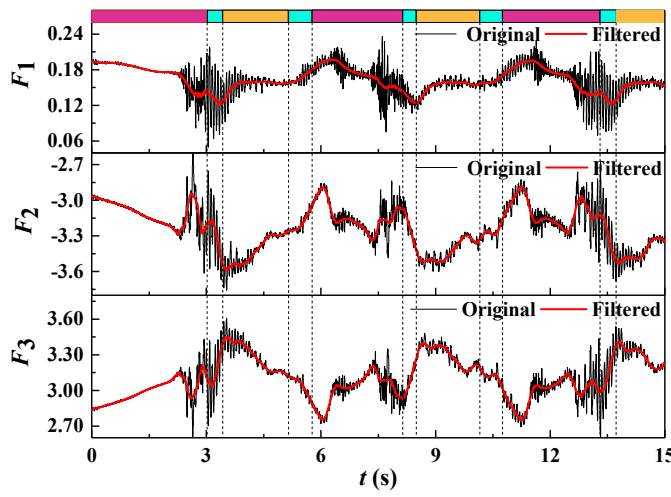

(a)

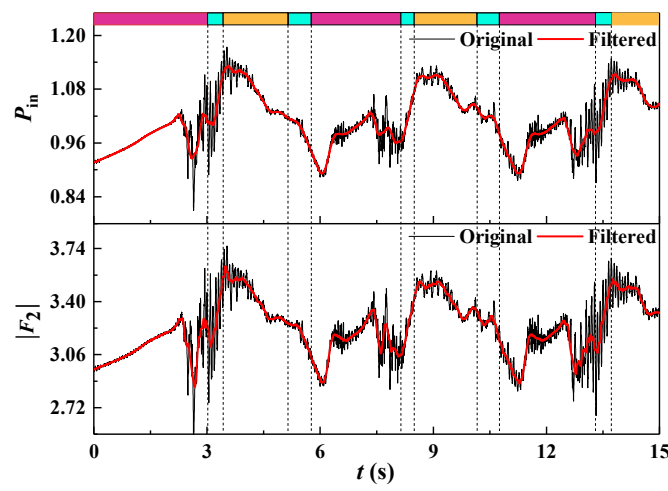

(b)

Figure 8. Histories of axial forces in CFC during the runaway transient process. (a) $F_{2}, F_{3}$ and $F_{1}$. (b) $\left|F_{2}\right|$ and pressure at the CHC inlet $P_{\text {in }}$.

\subsubsection{Radial Forces}

The total radial force $F_{\mathrm{r}}$ can be divided into the component $F_{\mathrm{x}}$ in the $x$-direction and the component $F_{\mathrm{y}}$ in the $y$-direction, namely, $F_{\mathrm{r}}=\left(F_{\mathrm{x}}{ }^{2}+F_{\mathrm{y}}{ }^{2}\right)^{0.5}$. In the rated operating condition, when the runner rotates for a cycle (the period is $0.12 \mathrm{~s}$ ), the radial forces in MFC and CFC together with the total radial force, show periodically change, not only in value, but also in direction (Figure $9 a, b$ ). The numbers of the peaks for MFC radial force and the total force in a cycle are equal to the blade number. According to the variation law of pressure in the middle span of the vaneless space (Figure 9c), it can be concluded that 
the change of radial force in the rated operating condition is mainly affected by stator-rotor interaction. The direction of $F_{\mathrm{x}}$ and $F_{\mathrm{y}}$ are shown in Figure $9 \mathrm{a}$, the $F_{\mathrm{x}}$ is perpendicular to the spiral casing inlet flow. Even though the flow patterns are smooth in the rated operating conditions, the $F_{\mathrm{x}}$ is greatly asymmetric and random due to the vortexes and backflow around the casing tongue and is dominated by the rotor-stator interference. The periodical change of $F_{\mathrm{X}}$ dominates the change of the total radial force, and the radial force in CFC is smaller than that in MFC (Figure 9d).

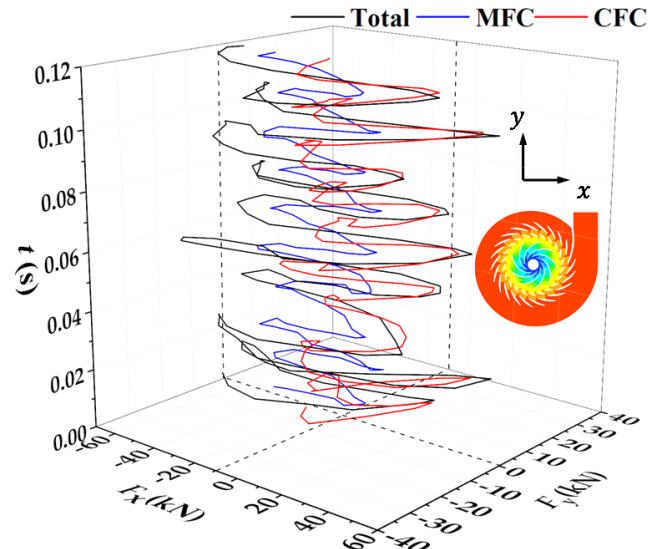

(a)

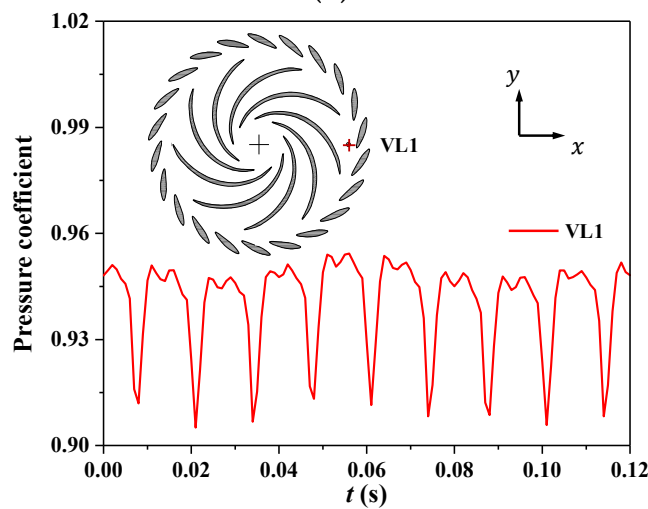

(c)

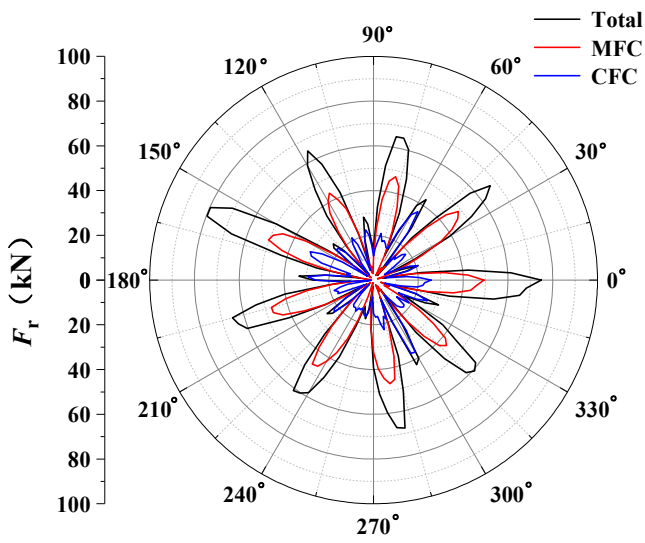

(b)

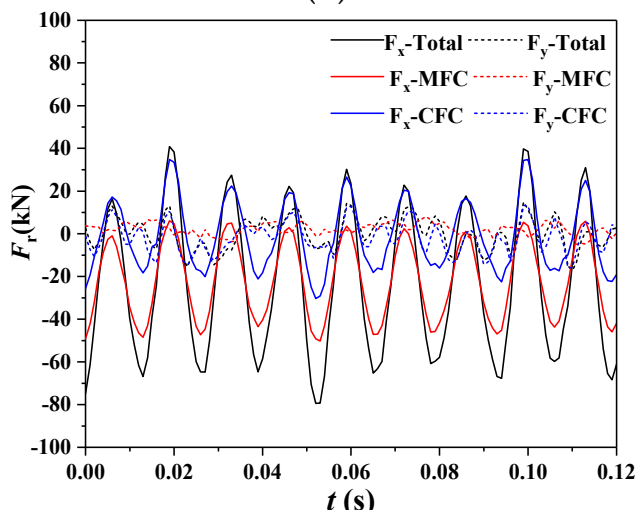

(d)

Figure 9. Variation laws of radial forces in a cycle at the rated working point. (a) The direction of radial forces. (b) Value of radial forces. (c) Histories of pressure in the vaneless space. (d) Oscillating laws of $F_{\mathrm{x}}, F_{\mathrm{y}}$.

During the runaway transient process, the total radial force increases more than 100 times and reaches the maximum when the working point approaching the runaway point. Its MFC component accounts for more than $70 \%$ and dominates the changing tread of the total radial force (Figure 10a,b). In MFC, when the working point closes to the runaway point, the radial velocity at the hub side rapidly decreases because of the extremely serious rotating stall, then the reverse flow occurs, which leads to a rapid increase of radial force in MFC (Figure 11). Until the working point enters the turbine braking mode, the reverse flow gradually transits from the hub side to the middle span, and becomes smooth, then the radial force decreases rapidly. When the working point re-enters the turbine mode, the intensity of the reverse flow at the middle span gradually decreases, and the rotating stalls in blade channels increases, causing the increases of the radial forces. Furthermore, the radial force in MFC is also influenced by the vortex rope, the number of guide vanes, and so on $[30,31]$, which would not be discussed in detail. In CFC, the radial forces in CHC and CSB show the same change trend (Figure 10c,d). Due to the larger radial projected area, the radial force in CSB is larger than that in CHC. According to Section 3.4.2, the strong rotating shear flow cannot generate the radial forces, while the secondary flow vortices in 
the radial direction can influence the radial forces in CFC. The strength of secondary flow vortices depends on the rotational speed of the rotating walls. The higher the rotational speed, the larger the centrifugal force and the radial velocity; the stronger the secondary flow vortices and the larger the radial force in CFC. Numerically, the fluctuation of runner radial forces is mainly caused by the flow evolution in MFC, however, the flow in CFC aggravates it.

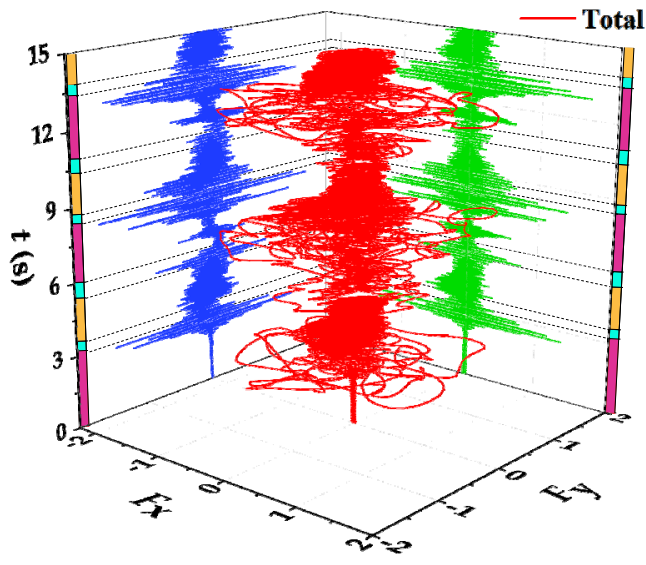

(a)

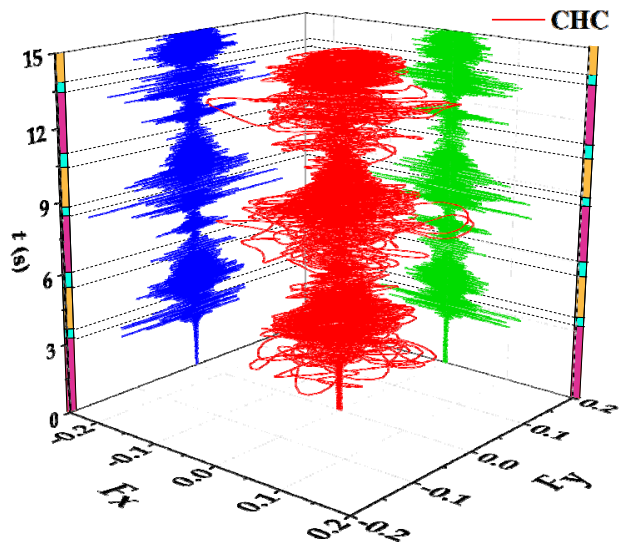

(c)

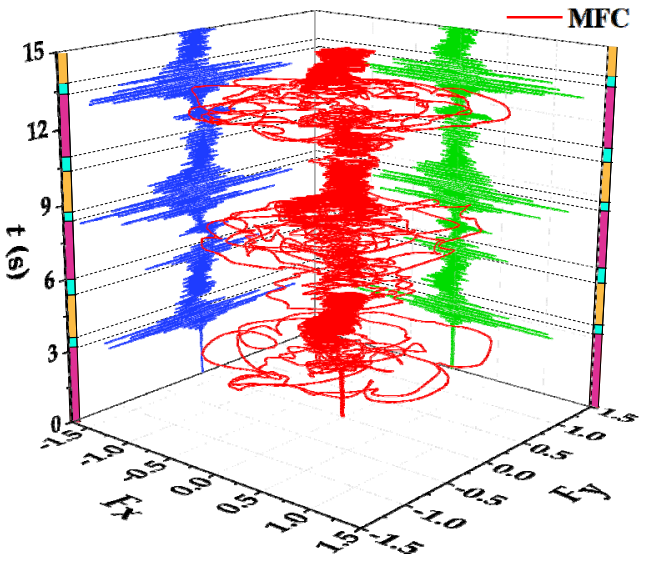

(b)

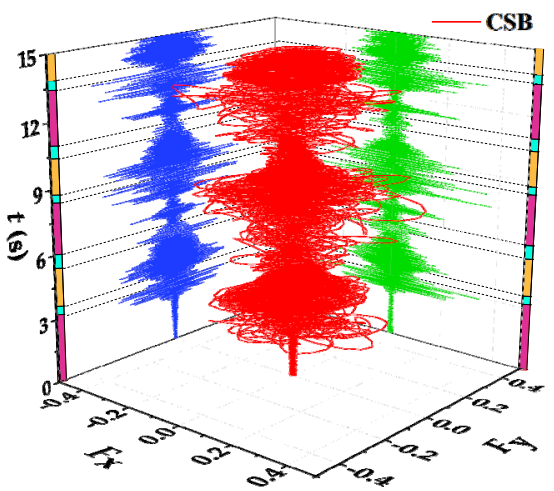

(d)

Figure 10. Variation laws of radial forces during the runaway transient process. (a) Total radial force. (b) Radial force in MFC. (c) Radial force in CHC. (d) Radial force in CSB.

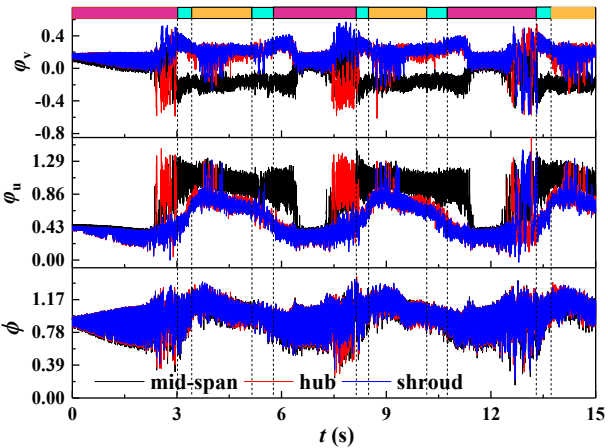

(a)

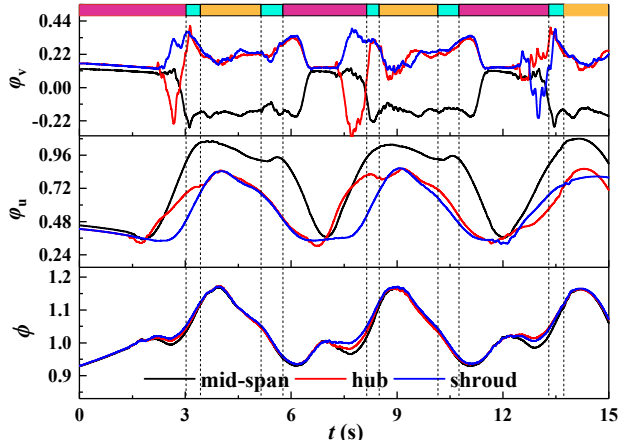

(b)

Figure 11. Radial velocity, circumferential velocity and pressure at the inlet of the runner during the runaway transient process. (a) Origin data. (b) Filtered data. 


\subsection{Pressure Distribution in $\mathrm{CHC}$ and Its Formulation}

\subsubsection{Pressure Distribution in $\mathrm{CHC}$}

At the rated working point, the pressure gradually decreases inward the MFC and $\mathrm{CHC}$, and the decrease degree in $\mathrm{CHC}$ is less than that in MFC (Figure 12a). At the sealing ring position of $\mathrm{CHC}$, the water flows into the cavity in a jet form; the strong jets from the small gaps lead to a huge energy dissipation due to the small size of the sealing ring. Therefore, the pressure drops sharply every time after passing through each labyrinth sealing ring. The pressure distribution is basically uniform along the circumferential direction, namely, there is no circumferential pressure gradient (Figure 12b).

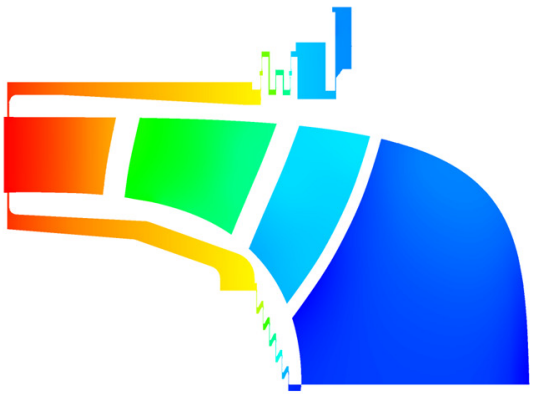

(a)

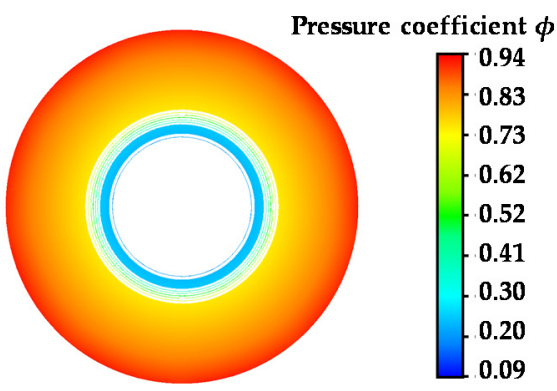

(b)

Figure 12. Pressure distribution at the rated working point. (a) Meridian section of whole flow channels. (b) Horizontal cross-section of CHC.

In order to investigate pressure fluctuations in $\mathrm{CHC}$, several pressure monitoring points on the plane of $x=0$ were set in CHC (Figure 13), where $P_{1}$ is the monitoring point at the vaneless space in MFC, which is located in front of $\mathrm{CHC}$ inlet; $\mathrm{P}_{2}$ to $\mathrm{P}_{8}$ are in $\mathrm{CHC}$; $\mathrm{P}_{9}$ is in the draft tube, which is located at the outlet of the pressure equalizing pipe. During the runaway transient process, the pressure changing trends of the measuring points in front of the sealing ring are consistent with that of $P_{1}$, while that behind the sealing ring are consistent with that of $\mathrm{P}_{9}$ (Figure 14). Therefore, it is the pressure change in MFC that dominates the pressure change in CHC. In addition, the pressure in CFC shows a few pulsating signals from MFC, which indicates that the severe pressure fluctuation in the vaneless space can be transmitted into the clearance region, but the pulsating amplitude decreases at a large scale, more than $75 \%$.

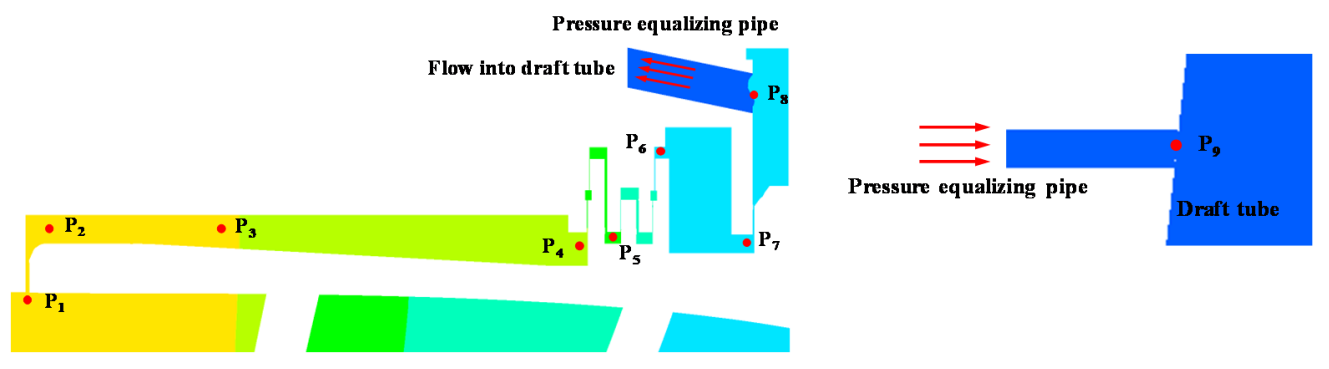

Figure 13. Arrangement of pressure monitoring points.

\subsubsection{Pressure Calculation in $\mathrm{CHC}$}

According to the pressure distribution in $\mathrm{CHC}$, the huge pressure is the main contributor to the large clearance forces. Therefore, accurate calculation of the clearance pressure can provide the basis for predicting the clearance forces. For the low specificspeed pump-turbine, the position of the sealing ring is relatively close to the shaft due to the relatively larger $D_{1} / D_{2}$, leading to a larger external cavity area and smaller internal cavity area. Moreover, the pressure in the external cavity is much higher than that in the internal cavity. Both of that result in a huge axial force in the external cavity, which is the dominant component of $\mathrm{CHC}$ forces. 


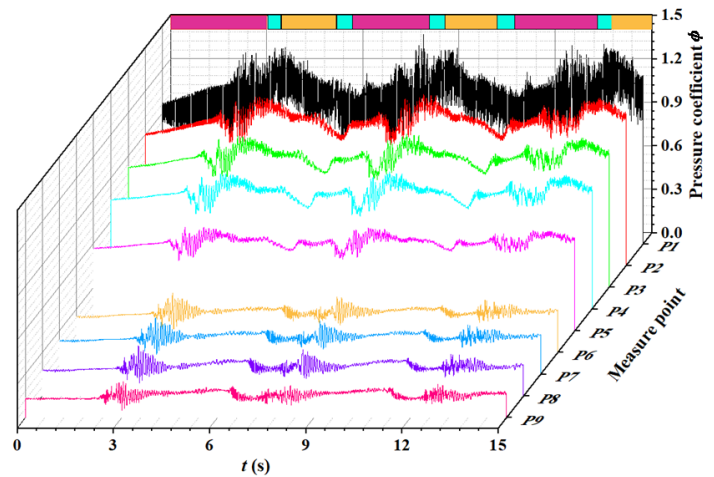

(a)

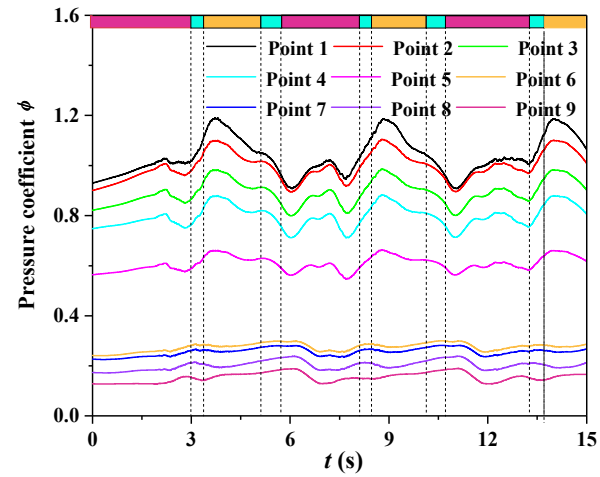

(b)

Figure 14. Pressure variation trend in $\mathrm{CHC}$ during the runaway transient process. (a) Original data. (b) Filtered data.

In $\mathrm{CHC}$, the strong rotating shear flow containing a velocity core region in the circumferential direction, and some secondary flow vortices in the meridian section, are formed (Section 3.4.2). Compared with the circumferential velocity, the secondary flow velocity is smaller than a tenth of the circumferential velocity and can be ignored for general analysis. Therefore, the surface forces are equal to the mass forces on any fluid mass in the radial direction (Figure 15), and Equation (11) can be listed based on the liquid equilibrium differential equation. Equation (11) can be simplified as Equation (12) as follows:

$$
\begin{gathered}
\left(p-\frac{\partial p}{\partial x}\right) \mathrm{d} y \mathrm{~d} z-\left(p+\frac{\partial p}{\partial x}\right) \mathrm{d} y \mathrm{~d} z+\rho f_{x} \mathrm{~d} x \mathrm{~d} y \mathrm{~d} z=0 \\
\frac{\partial p}{\partial x}=\rho f_{x}
\end{gathered}
$$

where $p$ is the pressure; $f_{x}$ is the mass force. For the water body in $\mathrm{CHC}$, the mass force is only the centrifugal force when ignoring the gravity. Assuming the core region rotational velocity is $k \omega$, we can modify Equation (12) to:

$$
\mathrm{d} p=\rho(k \omega)^{2} r
$$

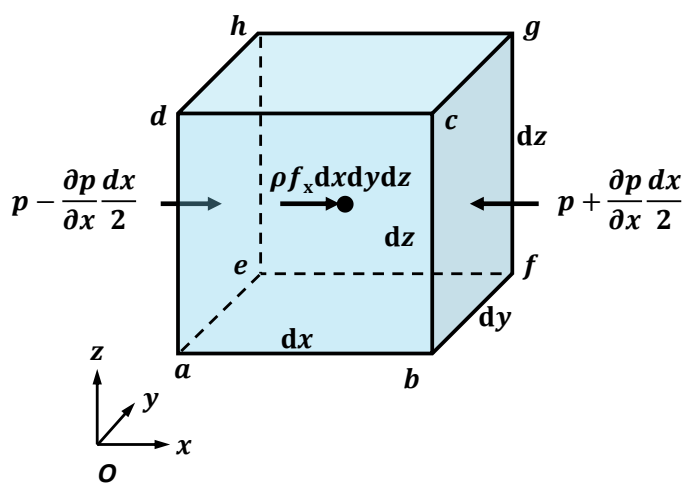

Figure 15. Forces diagram in $\mathrm{CHC}$.

By integrating Equation (13) from the CHC inlet to the sealing ring inlet, we obtain the radial pressure drop $\Delta P$ in the external cavity can be obtained as follows:

$$
\begin{gathered}
\int_{p}^{p_{\text {in }}} \mathrm{d} p=\int_{r}^{R_{1}} \rho(k \omega)^{2} r \mathrm{~d} r \\
\Delta P=\frac{\rho(k \omega)^{2}}{2}\left(R_{1}^{2}-r^{2}\right)
\end{gathered}
$$


where $\omega$ is the runner rotational speed; $k$ is an unknown coefficient, $r$ is the radius of the clearance area. From Equation (15), it can be seen that the pressure drop in CHC is proportional to the square of both the radius and the rotational speed.

In order to verify the correctness of Equation (15), the results from simulations are compared with those from Equation (15). Assuming a linear distribution for the circumferential velocity along the cavity height, $k$ is equal to 0.5 . The pressure drop in the external cavity $\Delta P$ calculated by Equation (15) and simulation do not match well (Figure 16a). However, when the two are in good agreement when let $k=0.475$, the two will agree well. Further study is needed to explore $k$ value and the core region velocity.

During the runaway transient process, the oscillating law of $\Delta P$ calculated by Equation (15) is basically consistent with the simulation result (Figure 16b). The rotating speed is the dominant factor for the $\Delta P$; the larger the rotating speed, the larger the centrifugal force, the larger the pressure drop $\Delta P$ in the clearance cavity. However, the simulated $\Delta P$ shows some pulsating signals from the $\mathrm{CHC}$ inlet.

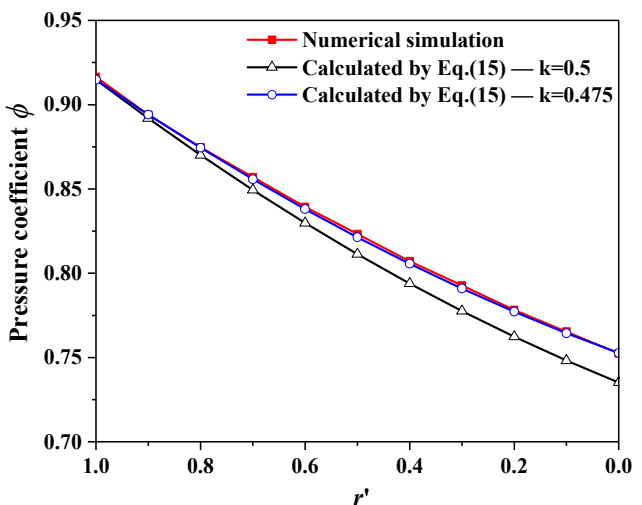

(a)

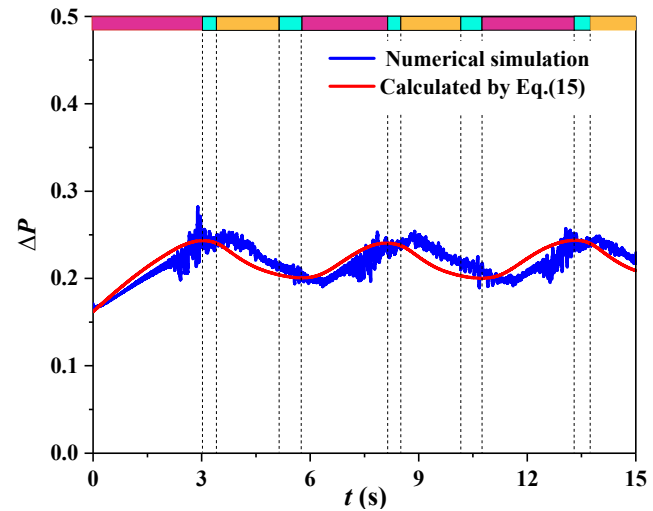

(b)

Figure 16. Pressure in the external cavity of $\mathrm{CHC}$. (a) Pressure distribution along the radial direction at the rated working point. (b) Changing laws of the pressure drop in the external cavity during the runaway transient process.

\subsubsection{Axial Force Formula}

According to the pressure drop formula, the pressure at any position in the external cavity can be calculated according to Equation (16). By integrating, the pressure, we can obtain the axial force in the external cavity $F_{\mathrm{o}}$ as follows:

$$
\begin{gathered}
P=P_{\mathrm{in}}-\frac{\rho(k \omega)^{2}}{2}\left(R_{1}^{2}-r^{2}\right) \\
F_{\mathrm{o}}=\int_{R_{\mathrm{m}}}^{R_{1}}\left[P_{\mathrm{in}} \frac{\rho(k \omega)^{2}}{2}\left(R_{1}^{2}-r^{2}\right)\right] 2 \pi r \mathrm{~d} r=\pi\left(R_{1}^{2}-R_{\mathrm{m}}^{2}\right)\left[P_{\mathrm{in}}-\frac{\rho(k \omega)^{2}\left(R_{1}^{2}-R_{\mathrm{m}}^{2}\right)}{4}\right]
\end{gathered}
$$

where $F_{\mathrm{o}}$ is the axial force of the external cavity; $P_{\mathrm{in}}$ is the inlet pressure of $\mathrm{CHC}$. Therefore, the clearance inlet pressure $P_{\text {in }}$ and the rotational speed $n$ are the influence factors of the clearance axial force.

Similarly, the axial force in the internal cavity can be calculated by integrating the internal cavity pressure. Thus, the axial force in $\mathrm{CHC}$ can be expressed as a function of the clearance inlet pressure and the rotational speed. With the runner structure parameters known, we can estimate the axial force in CFC by Equation (17).

\subsection{Flow Patterns in the Clearance Region}

\subsubsection{Streamline Distribution in Clearance Region}

In order to qualitatively understand the velocity distribution in $\mathrm{CHC}$, the streamlines in different height sections in $\mathrm{CHC}$ are shown in Figure 17. In the section $z / h=0$, namely, 
the upper surface of the hub, the outward spiral flow is formed due to the larger centrifugal force, while in the section $z / h=1$, the lower surface of the cover, the inward spiral flow is formed. In the middle section $(z / h=0.5)$, the radial velocity is close to zero, forming stable strong rotating shear flow. In the meridian section, the secondary flow vortices are shown in Figure 18. The pressure difference force is greater than the centrifugal force near the cover and the bottom ring, forming a radial inward flow boundary layer, while exactly opposite near the hub and shroud, where a radial outward flow boundary layer is formed. At the sealing ring position, the flow velocity greatly increases when passing through the sealing ring because of its small size, and the outflow flows into the cavity in a form of jet, which also forms secondary flow vortices.

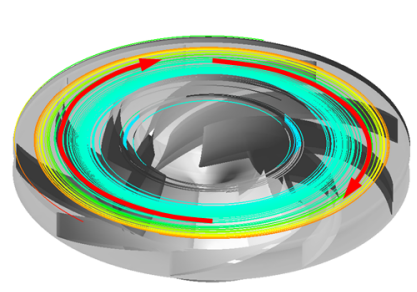

(a)

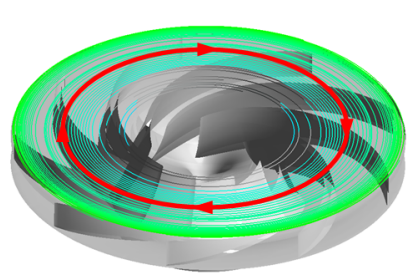

(b)

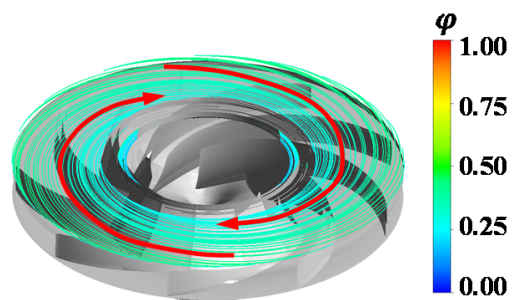

(c)

Figure 17. Streamline diagrams in different height sections in $\mathrm{CHC}$ at the rated working point. (a) $z / h=0$. (b) $z / h=0.5$. (c) $z / h=1$.

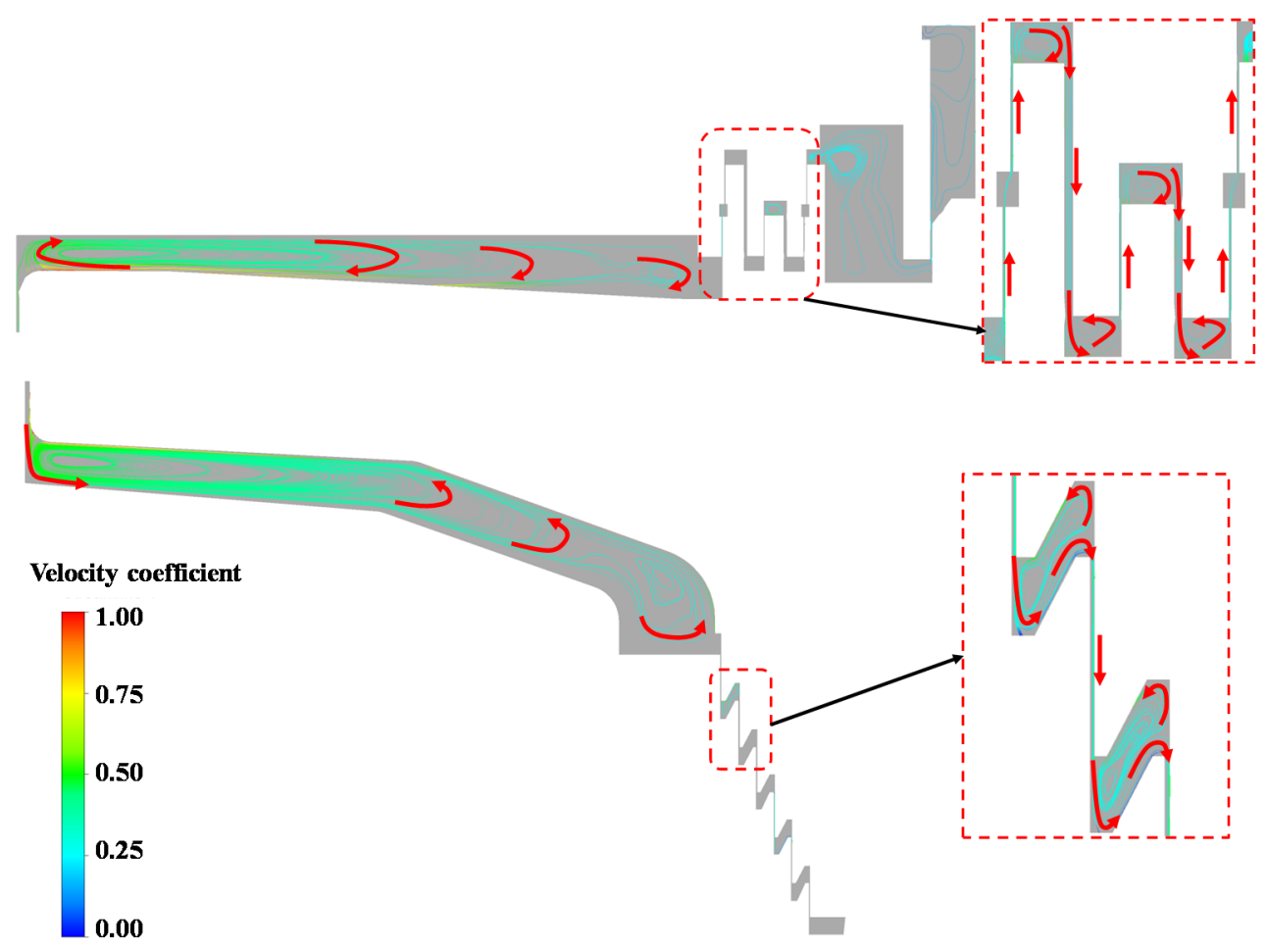

Figure 18. Streamline diagrams at the meridian section in $\mathrm{CHC}$ and $\mathrm{CBS}$ at the rated working point.

\subsubsection{Velocity Distribution in the Clearance Region}

In order to quantitatively analyze the velocity evolution in $\mathrm{CHC}$ during the runaway process, the velocity change histories at different radius and heights are shown below.

(1) Circumferential velocity distribution

At the rated working point, a velocity core region is formed in the circumferential direction. The circumferential velocity reaches its maximum on the rotating wall, while reduced to zero on the stationary wall, and is between those two for the core region 
(Figure 19a). The velocity core region rotates with a fixed circumferential velocity at the fixed radius similar to a rigid body. The larger the radius, the greater the core region circumferential velocity. From the previous studies, the clearance cavity of a pump-turbine is similar to a thin-layer cavity composed of two disks, in which one disk is stationary and the other is rotating. Batchelor [32] first analyzed the flow between a rotating wall and a stationary wall with infinite boundary and found that the fluid in the central region rotated with a fixed angular velocity. Mukherjee [33] tested fluid in finite rotating and stationary disks, and a velocity core region was also observed when the cavity height was large. Then Singh [34] found that the fluid in the core region rotated with a rotational speed lower than that of the rotating disk. The above existing research on the flow between a rotating wall and a stationary wall proves the correctness of this numerical calculation of clearance flow.

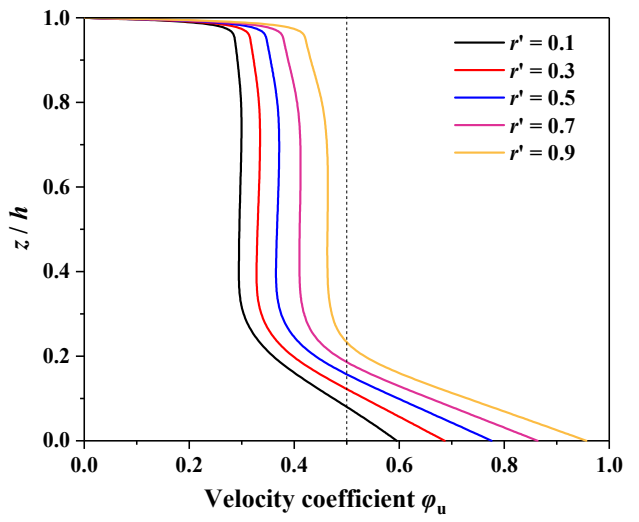

(a)

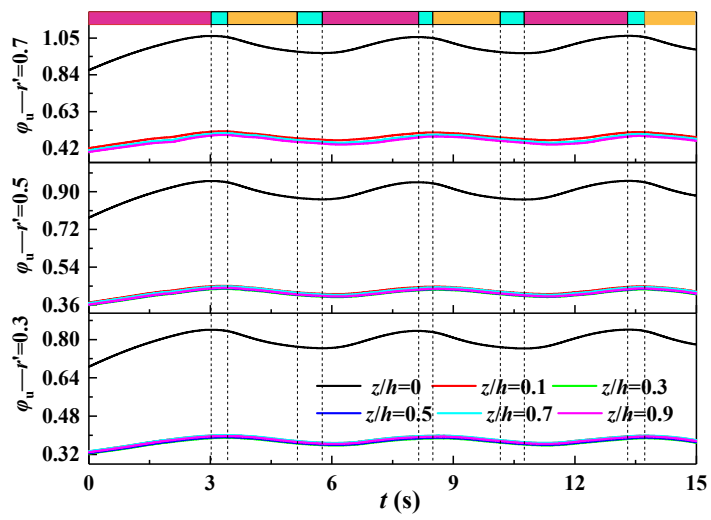

(b)

Figure 19. Circumferential velocity distribution along the cavity height in CHC. (a) Rated operating condition. (b) Runaway transient process.

During the runaway transient process, the velocity core region is still maintained, its velocity changes with the rotating speed (Figure 19b). Similarly, the circumferential velocity near the rotating wall is always the largest. With the increase of rotational speed, the velocity in the core region and the viscous force on the rotating wall become larger.

(2) Radial velocity distribution

Radial velocity along the cavity height direction at different radii is shown in Figure 20a. The flow is outward around the rotating wall, while inward around the stationary wall, and the radial velocity is about zero at the middle height of the cavity. Compared with the circumferential velocity, the radial velocity is smaller than a tenth of the circumferential velocity. During the runaway transient process, the radial velocity changes with the rotating speed (Figure 20b). The larger the rotating speed of the rotating wall, the greater the centrifugal force, the stronger intensity of the secondary flow vortices and the larger the radial velocity. 


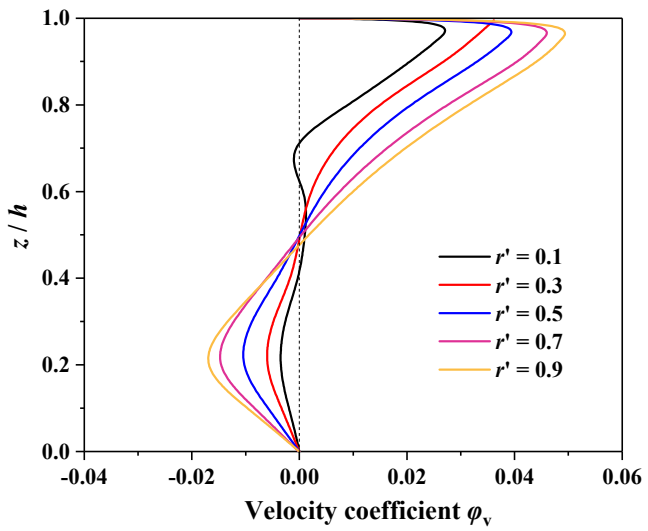

(a)

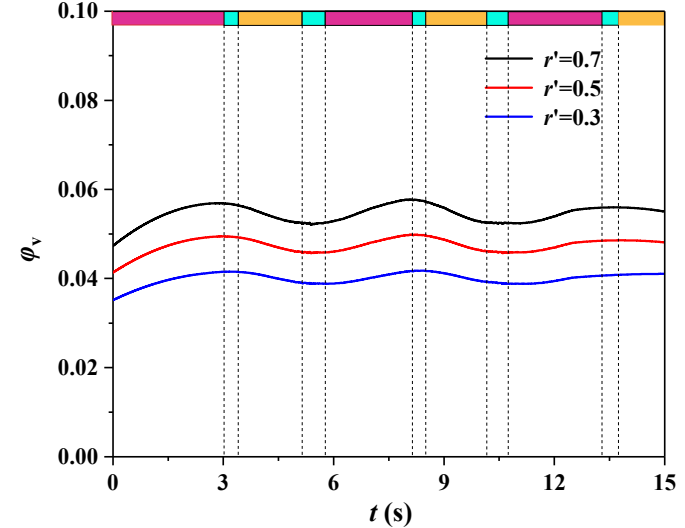

(b)

Figure 20. Radial velocity distribution along cavity height in CHC. (a) Rated operating condition. (b) Runaway transient process.

\section{Conclusions}

In this study, the runaway oscillating process of a low specific-speed pump-turbine was simulated by using 3D CFD software. By analyzing the flow patterns, pressure distribution and dynamic hydraulic forces in $\mathrm{CFC}$, we obtained the formulas for estimating the axial hydraulic forces in both MFC and CFC, as well as their influence factors and change mechanism, which benefits to a professional runner design. We found that the CFC component of the total runner axial hydraulic force shows a similar significance level to the MFC component during transient processes, and this component should be considered when studying the runner forces. The detailed conclusions are as follows:

(1) During the runaway oscillating process, the total runner axial hydraulic force $F_{\mathrm{W}}$ periodically fluctuates with large amplitudes, and reaches the upward maximum before the runaway point, while comes up to the downward maximum in turbine braking mode. This axial hydraulic force can be quantified by the components in MFC and CFC. The component in MFC can be formulated as a function of the momentum changing rate and the runner outlet axial pressure, while the CFC component as a function of the clearance inlet pressure and rotational speed.

(2) The fluctuation of runner radial force is mainly caused by the flow evolution in MFC, however, the flow in CFC aggravates it. During the runaway process, the extremely serious rotating stall in MFC leads to the rapid increase of radial force in MFC when the working point closes to the runaway point. For the radial force in CFC, the rotational speed is the main influence factor.

(3) It is the pressure change in MFC that dominates the pressure change in $\mathrm{CHC}$. The radial pressure drop $\Delta P$ in the external cavity of $\mathrm{CHC}$ can be formulated as a function of the square of both the radius and rotational speed. The pressure in CFC shows a few pulsating signals from MFC, indicating that the severe pressure fluctuation in the vaneless space can be transmitted into the clearance region, but the amplitude greatly decreases.

Even though we have found the velocity core region in the clearance region, its magnitude and influence factors are still unclear. In order to accurately calculate the clearance pressure and axial hydraulic force, the velocity value of the core region needs to be further studied.

Author Contributions: Data curation, X.H. and Z.Y.; formal analysis, X.H.; investigation, X.H.; validation, Z.Y.; writing-original draft preparation, X.H. and Y.C.; writing-review and editing, K.L., X.Z. and D.L. All authors have read and agreed to the published version of the manuscript.

Funding: This work was supported by the National Natural Science Foundation of China (NSFC) (Grant Nos. 51839008 and 51909226), the Natural Science Foundation of Fujian Province, China (Grant No. 2018J01525) and the China Postdoctoral Science Foundation (Grant No. 2020M673568XB). 
Institutional Review Board Statement: Not applicable.

Informed Consent Statement: Not applicable.

Data Availability Statement: Not applicable.

Acknowledgments: The numerical simulations were conducted on the supercomputing system in the Supercomputing Center of Wuhan University.

Conflicts of Interest: The authors declare no conflict of interest.

\section{Abbreviations}

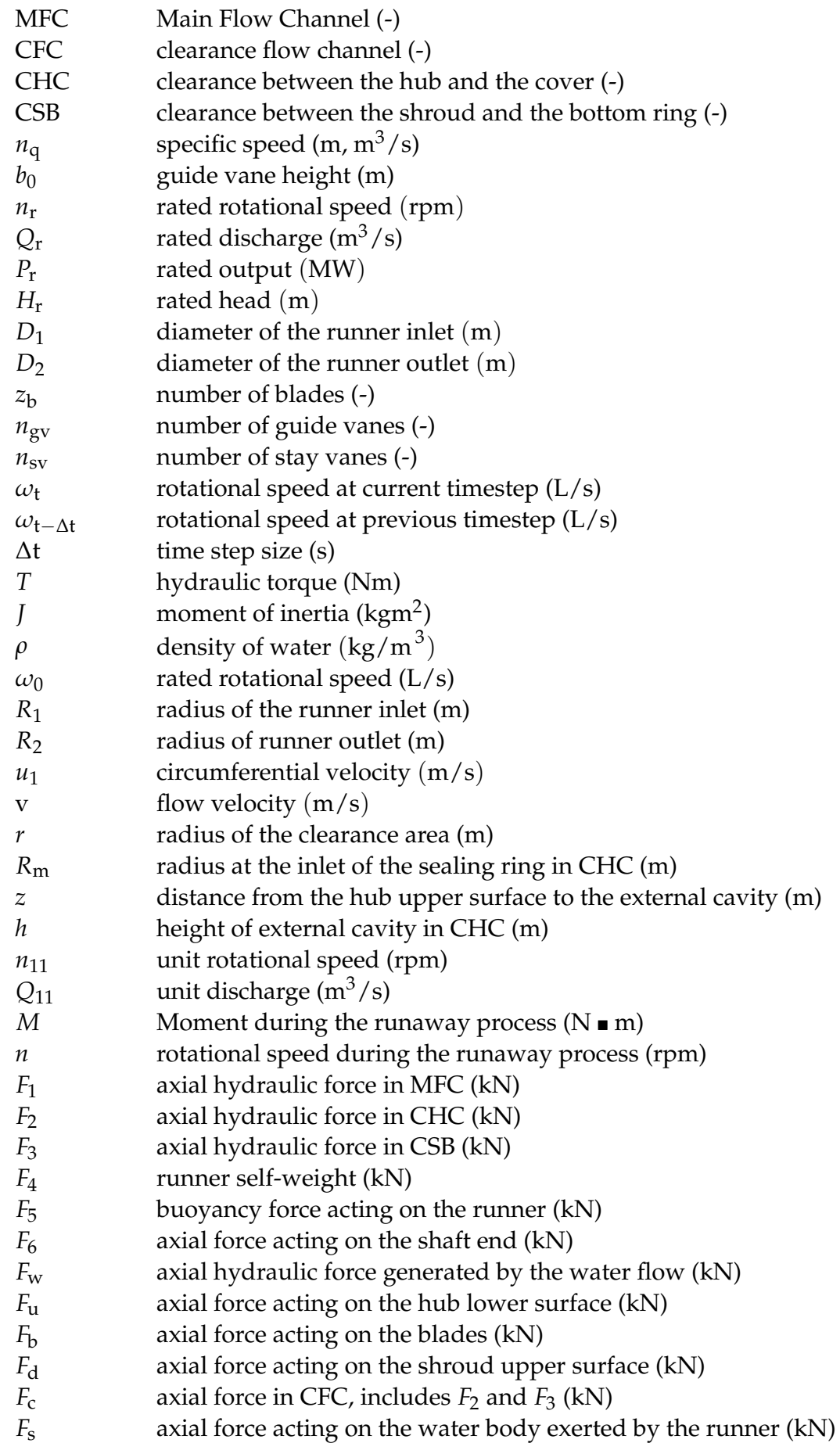




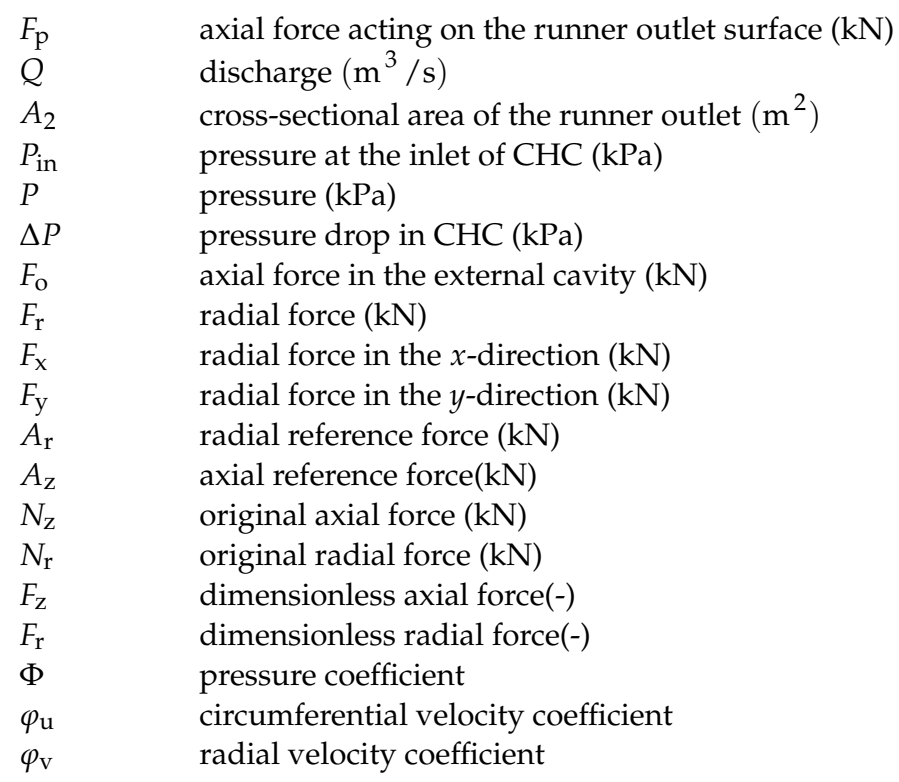

\section{References}

1. Landry, M.; Gagnon, Y. Energy Storage: Technology Applications and Policy Options. Energy Procedia 2015, 79, 315-320. [CrossRef]

2. Kong, Y.; Kong, Z.; Liu, Z.; Wei, C.; Zhang, J.; An, G. Pumped storage power stations in China: The past, the present, and the future. Renew. Sustain. Energy Rev. 2017, 71, 720-731. [CrossRef]

3. Yao, Z.; Bi, H.; Zhuang, X.; Huang, Q.; Zhi, F.; Wang, Z. Simulation and analysis of transient process for Guangzhou pumped storage power plant A. J. Hydroelectr. Eng. 2015, 34, 176-181. (In Chinese)

4. Goyal, R.; Gandhi, B.K. Review of hydrodynamics instabilities in Francis turbine during off-design and transient operations. Renew. Energy 2018, 116, 697-709. [CrossRef]

5. Cai, J.; Zhou, X.; Deng, L.; Zhang, W. The research of the abnormal water hammer phenomenon based on the unit 3 over speed test of Jiangsu Yixing pumped storage power Station. Water Power 2009, 2, 76-79. (In Chinese)

6. Le, Z.; Kong, L. Cause analysis on rotating part lifting of Unit 2 in Tianhuangping Pumped Storage Plant. Mech. Electr. Tech. Hydropower Stn. 2005, 28, 11-14. (In Chinese)

7. Wei, B.; Ji, C. Study on rotor operation stability of high-speed large-capacity generator-motor: The accident of rotor pole in Huizhou pumped-storage power station. Water Power 2010, 36, 57-60. (In Chinese)

8. Dai, Y.; Wang, H.; Zhang, K.; Zheng, L.; You, G.; Kong, L.; Zhu, X.; Lou, Y. Research on axial hydraulic thrust of Francis pump-turbine's runner. J. Hydroelectr. Eng. 2005, 24, 105-113. (In Chinese)

9. Xia, L.; Cheng, Y.; You, J.; Zhang, X.; Yang, J.; Qian, Z. Mechanism of the S-Shaped Characteristics and the Runaway Instability of Pump-Turbines. J. Fluids Eng. 2016, 139, 031101. [CrossRef]

10. Xia, L.; Cheng, Y.; Yang, Z.; You, J.; Yang, J.; Qian, Z. Evolutions of Pressure Fluctuations and Runner Loads During Runaway Processes of a Pump-Turbine. J. Fluids Eng. 2017, 139, 091101. [CrossRef]

11. Yang, Z.; Cheng, Y.; Xia, L.; Meng, W.; Liu, K.; Zhang, X. Evolutions of flow patterns and pressure fluctuations in a prototype pump-turbine during the runaway transient process after pump-trip. Renew. Energy 2020, 152, 1149-1159. [CrossRef]

12. Widmer, C.; Staubli, T.; Ledergerber, N. Unstable Characteristics and Rotating Stall in Turbine Brake Operation of Pump-Turbines. J. Fluids Eng. 2011, 133, 041101. [CrossRef]

13. Fu, X.L.; Li, D.Y.; Wang, H.J.; Zhang, G.H.; Wei, X.Z.; Qin, D.Q. Investigation on the fluctuation of hydraulic exciting force on a pump-turbine runner during the load rejection process. IOP Conf. Ser. Earth Environ. Sci. 2018, 163, 012101. [CrossRef]

14. Huang, L.; Huang, P.; Cheng, G.; Li, M.; Liu, Y. Numerical simulation of flow field and leakage rate in labyrinth seal. Hunan Electr. Power 2007, 27, 1-4. (In Chinese)

15. Le Roy, V.; Guibault, F.; Vu, T.C. Validation of a CFD model for hydraulic seals. Int. J. Fluid Mach. Syst. 2009, 2, 400-408. [CrossRef]

16. Kim, T.S.; Cha, K.S. Comparative analysis of the influence of labyrinth seal configuration on leakage behavior. J. Mech. Sci. Technol. 2009, 23, 2830-2838. [CrossRef]

17. Jia, X.; Zheng, Q.; Jiang, Y.; Zhang, H. Leakage and rotor dynamic performance of T type labyrinth seal. Aerosp. Sci. Technol. 2019, 88, 22-31. [CrossRef]

18. Zhao, W.; Nielsen, T.K.; Billdal, J.T. Effects of cavity on leakage loss in straight-through labyrinth seals. IOP Conf. Ser. Earth Environ. Sci. 2010, 12, 012002. [CrossRef]

19. Wang, W.; Su, S.; Yan, Y. Study on comb labyrinth seals of Francis turbine at different Reynolds. Appl. Mech. Mater. 2014, 444, 423-426. [CrossRef]

20. Koirala, R.; Zhu, B.; Neopane, H.P. Effect of Guide Vane Clearance Gap on Francis Turbine Performance. Energies 2016, 9, 275. [CrossRef] 
21. Dong, Z. Numerical Analysis of Clearance Flow in Francis Pump-Turbine. Master's Thesis, Lanzhou University of Technology, Lanzhou, China, 2013. (In Chinese)

22. Jürgen, S.; Helmut, B.; Helmut, J. Analysis of the leakage behavior of Francis turbines and its impact on the hydraulic efficiency-A validation of an analytical model based on computational fluid dynamics results. J. Fluids Eng. 2017, $139,021106$.

23. Čelič, D.; Ondráčka, H. The influence of disc friction losses and labyrinth losses on efficiency of high head Francis turbine. J. Phys. Conf. Ser. 2015, 579, 012007. [CrossRef]

24. Wu, G.; Zhang, K.; Dai, Y. Influence of the runner gap and seal construction on the safety in operation of Francis water power sets. Large Electr. Mach. Hydraul. Turbine 2005, 1, 44-48. (In Chinese)

25. Wu, G.; Zhang, K.; Dai, Y.; Sun, J. Influences of the leakage rate of low specific speed Francis runner on phenomenon of the lifting hydroelectric generator set. J. Hydroelectr. Eng. 2004, 23, 106-111. (In Chinese)

26. Fu, X.; Li, D.; Wang, H.; Zhang, G.; Li, Z.; Wei, X. Influence of the clearance flow on the load rejection process in a pump-turbine. Renew. Energy 2018, 127, 310-321. [CrossRef]

27. Zhang, J. Numerical Simulation of Multi-Scale Flows in Francis Turbine and Research on Hydraulic Stability of Transient Processes. Master's Thesis, Hohai University, Nanjing, China, 2017. (In Chinese)

28. Liu, D.; Zhang, X.; Yang, Z.; Liu, K.; Cheng, Y. Evaluating the pressure fluctuations during load rejection of two pump-turbines in a prototype pumped-storage system by using 1D-3D coupled simulation. Renew. Energy 2021, 171, 1276-1289. [CrossRef]

29. Yang, Z.; Liu, Z.; Cheng, Y.; Zhang, X.; Liu, K.; Xia, L. Differences of Flow Patterns and Pressure Pulsations in Four Prototype Pump-Turbines During Runaway Transient Processes. Energies 2020, 13, 5269. [CrossRef]

30. Dörfler, P.; Lohmberg, A.; Michler, W.; Sick, M. Investigation of Pressure Pulsation and Runner Forces in a Single-Stage Reversible Pump Turbine Model. In Proceedings of the 11th IAHR International Meeting of the Workgroup on the Behaviour Machinery and Steady Oscillatory Conditions, Stuttgart, Germany, 8-10 October 2003.

31. Dörfler, P.; Sick, M.; Coutu, A. Flow-Induced Pulsation and Vibration in Hydroelectric Machinery; Springer: London, UK, 2013.

32. Batchelor, G.K. Note on a Class of Solutions of the Navier-Stokes Equations Representing Steady Rotationally-Symmetric Flow. Q. J. Mech. Appl. Math. 1951, 4, 29-41. [CrossRef]

33. Mukherjee, A.; Steinberg, V. Von Kármán swirling flow between a rotating and a stationary smooth disk: Experiment. Phys. Rev. Fluids 2018, 3, 014102. [CrossRef]

34. Singh, A. Theoretical Investigation on Inflow between Two Rotating Disks. J. Fluids Eng. 2017, 139, 111202. [CrossRef] 